\title{
Anatomic Descriptive Technique Using the Posterior Leaflet of Mitral Valve to Tailor and Construction of a Posterior Bi-Leaflet for Correction of Mitral Valve Insufficiency
}

ISSN: 2578-0379

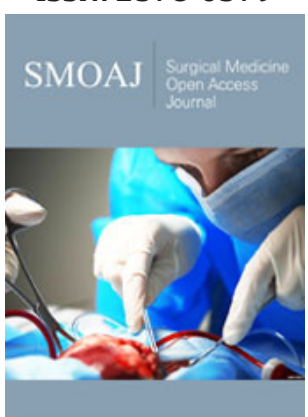

*Corresponding author: Mario César Santos de Abreu MD PHD, Department of Surgery, Faculty of Medicine, Federal University of Bahia, Brazil

Submission: 侮June 19, 2019

Published: 制June 24, 2019

Volume 2 - Issue 4

How to cite this article: Mário C S de Abreu, Valmir N R J, Mario C C, Ediriomar P, Marcos Mello B, et al. Anatomic Descriptive Technique Using the Posterior Leaflet of Mitral Valve to Tailor and Construction of a Posterior Bi-Leaflet for Correction of Mitral Valve Insufficiency. Surg Med Open Acc J.2(5). SMOAJ.000546.2019. DOI: $10.31031 /$ SMOAJ.2019.02.000546.

Copyright@ Mario César Santos de Abreu, This article is distributed under the terms of the Creative Commons Attribution 4.0 International License, which permits unrestricted use and redistribution provided that the original author and source are credited.

\section{Mário César Santos de Abreu ${ }^{1 *}$, Valmir Nascimento Rastely Júnior ${ }^{2}$, Mario Castro Carreiro ${ }^{1}$, Ediriomar Peixoto ${ }^{1}$, Marcos Mello Borba ${ }^{1}$, Normand Araújo Moura $^{1}$, Pedro Guimarães ${ }^{1}$, Martha Silvia Martinez-Silveira ${ }^{3}$, Hadarsa Cristina Pereira e Pereira ${ }^{5}$, Eduardo José Andrade Lopes ${ }^{4}$, Álvaro Rabelo Júnior ${ }^{1}$}

${ }^{1}$ Department of Surgery, Faculty of Medicine, Federal University of Bahia, Brazil

${ }^{2}$ Faculty of Medicine, Federal University of Bahia, Brazil

${ }^{3}$ Fundação Osvaldo Cruz, Brazil

${ }^{4}$ Nina Rodrigues Medical Legal Institute, Brazil

${ }^{5}$ Hospital Geral (HTO), Feira de Santana, Brazil

\begin{abstract}
Introduction: The mitral insufficiency as a result of the rheumatic fever in young population has important complications augmenting the morbidity and mortality of the valvar disease. In order to prevent mitral valve replacement, we designed a technique for correction of the mitral insufficiency, based in duplicating the coaptation surface of the posterior mitral leaflet.
\end{abstract}

Objectives: Describe anatomically the proposition technique for correction of the mitral insufficiency preserving the mitral valve.

Material and Methods: The technique designed is based in augmenting the coaptation surface of the mitral valve duplicating the posterior leaflet of the mitral valve; the approach to the mitral valve is via left atrium and the posterior leaflet is dissected from posterior annulus; the posterior annulus is diminished in diameter with stitches at the posterior mitral annulus; the mitral valve free from the edge is incised and divided in two leaflets (right and left posterior leaflets); near the anterior commissure the left leaflet is sutured to the mitral annulus portion and the right leaflet is sutured by running suture to the free edge of the left leaflet; after we tested the valve injecting electronic solution.

Conclusion: This technique promises to be a new proposition in the treatment of the mitral insufficiency, because is easy to do, but the appropriate timing of mitral plasty is the most important factor for the treatment and for the results.

Keywords: Mitral valve insufficiency; Rheumatic mitral valve disease; Mitral valve; Surgery-new technique

\section{Introduction}

The mitral insufficiency as a result of the rheumatic fever in young population has important complications augmenting the morbidity and mortality of the valvar disease (Figure 1). The main goal of the surgical treatment is treating mitral valve before the fibrous repairing post inflammatory process. One of the most important problems concerning mitral valve disease is mitral valve insufficiency. A great number of patients needs correction of this pathology, mainly associated with a number of diseases [1,2]. So, we designed a new technique for correction of the mitral insufficiency, based in duplicating the coaptation surface of the posterior mitral leaflet and preserving the mitral valve (Figure 2). The main objective of this is establish parameters that should be following during treating mitral valve insufficiency in an early phase, by this technique, without using any kind of heterologous tissue. This article is an anatomical description of a novel proposition for correction of mitral valve insufficiency [3-5]. 


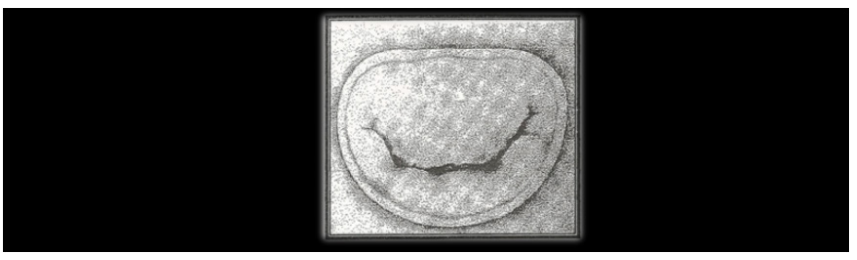

Figure 1: Schematic drawing of Mitral Insufficiency: First, we have to study the anatomy of the mitral valve apparatus to decide the best approach for correction of the mitral valve.

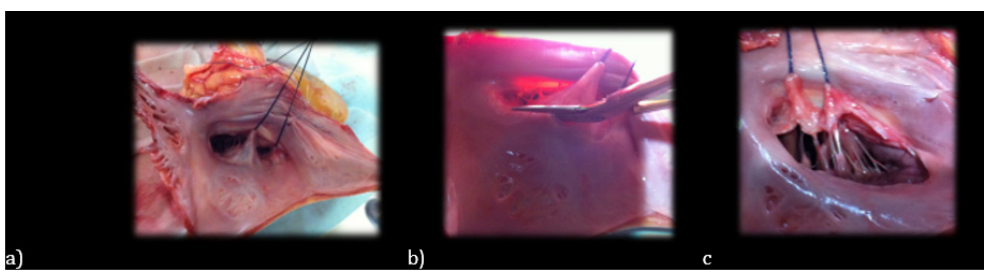

Figure 2: a) Shows a particular vision of the posterior mitral leaflet, which is dissected from the posterior annulus of the mitral;

b) and initiate at the anterior commissure and terminates at the posterior commissure;

c) so, the posterior leaflet is completely free from the mitral annulus.

\section{Material and Methods}
A. Anatomic study of posterior mitral leaflet
B. Division of the posterior leaflet
C. Duplication of the mitral leaflet

\section{Discussion}

The mitral insufficiency as a result of the rheumatic fever in young population has important complications augmenting the morbidity and mortality of the valvar disease [6,7]. The gold standard exam for detected valvar incompetence is the echocardiographic and Doppler imaging [12] . One and five years after the acute attack, the presence of mitral and aortic disease-insufficiency have been detected, even though no auscultatory abnormality, and should be highlighted that subclinical lesions are not transient [8-11]. Is frequent detection of valvular lesions that should be evaluated, and appropriate treatment for the valvar lesion, in time that is possible to correct the hemodynamically affection of the mitral lesions, before damaged of the valves itself, myocardium and pulmonary vessels [12-14].

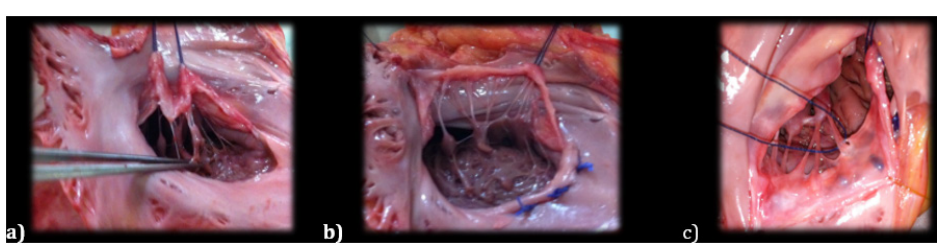

Figure 3: a) Shows the cut of the secondary and tertiary papillary muscles, in order to liberate the posterior leaflet;

b) initiate a plication suture with $U$ stitches to constrict the annulus.

c)Put two reference stitches to see the right and left papillary muscles.

An evidence that left ventricular dilation and heart failure in patients with acute rheumatic carditis is a consequence of hemodynamically significant regurgitant valve lesions were clarify by Essop and cols [11]. The Apparatus of the Mitral Valve in continuity with the papillary muscles has great importance in the result of mitral valve surgery, preserving this anatomical structure will define better outcomes [6,7]. The early calcification of bioprosthetic valve in young patients limit this indication and remains a difficult decision. In order to prevent frequently pulmonary hypertension, by the failure of the muscular support of the left ventricle, preservation of chordae tendineae is too much important to maintain left ventricle function [15] There are many ways of mitral valve reconstruction and a lot of surgical techniques reproducible by many emphatic cardiac surgeons with excellent long-term results [3-5]. From 1975, patients have been treated, by use of the new mitral plication suture and that reduced the number of mitral valve replacement (Figure 4). 


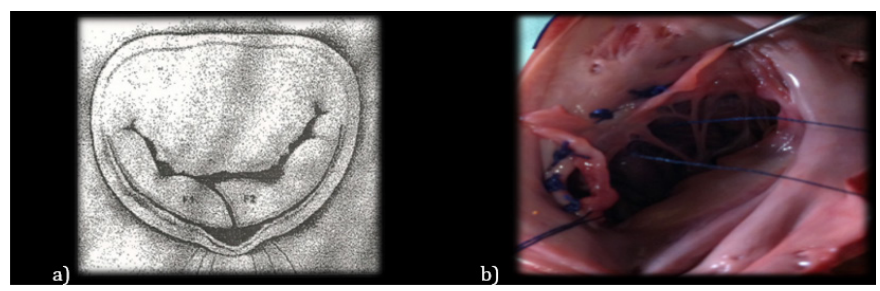

Figure 4: a) Division of the posterior leaflet.

b) This is a particular vision of the posterior mitral leaflet, which is dissected from the posterior annulus of the mitral, and now we divide the posterior leaflet in two parts, cutting in "S italica", this is important-it's not a transversal cut.

A study demonstrates that in rheumatic patients' mitral regurgitation could be treated effectively by annuloplasty without prosthetic annular support, evaluated at four months to 17years, making this observation an important issue mainly for the treatment of young patients [5]. As early we operated on our patients, better is the outcome; and this is not a premature surgery but a safe method

to treat these patients (Figure 5). So, in the light of these supporting literature, we designed this technique, using the posterior mitral leaflet to expand the coaptation area, and plication of posterior mitral annulus as one more approach and an effort to preserve their own valve structure to treat the mitral valve insufficiency. This is an anatomical study of this novel proposal (Figure 6).

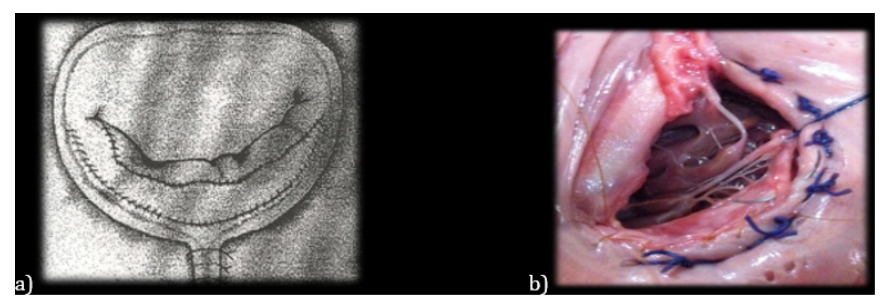

Figure 5: a) Duplication of the mitral leaflet.

b) we initiate a very delicate running suture beginning at the posterior commissure, we use prolene stitches 4-0, until finish the implantation of the left part of the posterior leaflet; an important point is not to stress the papillary muscles, to preserve the mobility of the posterior leaflet.

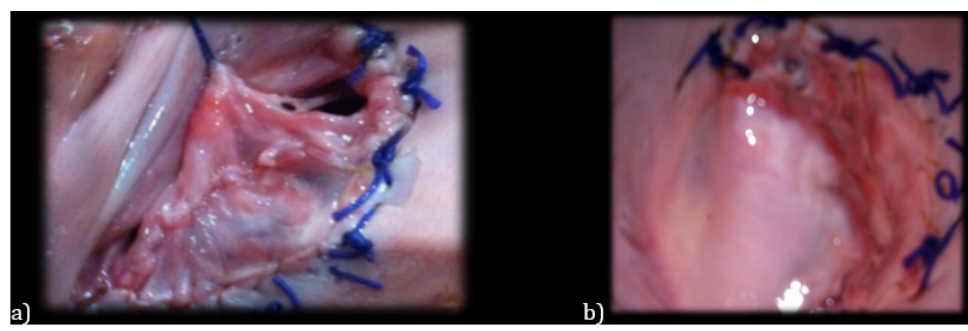

Figure 6: a) Shows the sequence of the procedure with suture, from the posterior commissure, initiating the implantation of the right portion of the posterior leaflet at the annulus and continuing down the free edge of the left portion of the mitral so the final aspect of the posterior leaflet is the duplicating leaflet, augmenting the surface of coaptation of the posterior leaflet;

b) Finally, it was tested the valve with ringer solution, and after surgery we made an echocardiogram study during surgery.

\section{Conclusion}

This technique promises to be one more approach and an advance in the treatment of the mitral insufficiency because is easy to do, but the appropriate timing of mitral plasty is the most important factor for the treatment and the results. The main limitation is to make a right choice, among so many possibilities, but for sure this will be one of the possibilities in selected patients.

\section{Acknowledgement}

We thank the director of the Institute of Legal Medicine of Bahia, Brazil, Dr. Mário Câmara Lopes Pontes, and the designer Sergio Martins for the support.

\section{References}

1. Ahmed MI, McGiffin DC, O’Rourke RA, Dell'Italia LJ (2009) Mitral regurgitation. Curr Probl Cardiol 34(3): 93-136. 
2. Matsuda H, Nakao M, Nohara H, Higami T, Mukohara N, et al. (1990) The causes of prolonged postoperative respiratory care in mitral valve disease with a giant left atrium. Kyobu Geka 43(3): 172-177.

3. Kalangos A (2012) The rheumatic mitral valve and repair techniques in children. Semin Thorac Cardiovasc Surg Pediatr Card Surg Annu 15(1): 80-87.

4. Rankin JS, Burrichter CA, Walton SMK, Whiteside JH, Teague SM, et al (2009) Trends in mitral valve surgery: A single practice experience. J Heart Valve Dis 18(4): 359-366.

5. Pomerantzeff PM, Brandão CM, Faber CM, Grinberg M, Cardoso LF, et al. (2000) Mitral valve repair in rheumatic patients. Heart Surg Forum 3(4): 273-276.

6. Carabello BA, Williams H, Gash AK, Kent R, Belber D, et al. (1986) Hemodynamic predictors of outcome in patients undergoing valve replacement. Circulation 74(6): 1309-1316.

7. Berrebi AJ, Carpentier SM, Phan KP, Nguyen VP, Chauvaud SM, et al. (2001) Results of up to 9years of high-temperature-fixed valvular bioprostheses in a young population. Ann Thorac Surg 71(5 Suppl): S353-5.

8. Fiddler GI, Gerlis LM, Walker DR, Scott O, Williams GJ (1983) Calcification of glutaraldehyde-preserved porcine and bovine xenograft valves in young children. Ann Thorac Surg 35(3): 257-261.
9. Willem F, Meuris B, De Visscher G, Cunanan C, Lane E, et al. (2008) Trilogy pericardial valve: Hemodynamic performance and calcification in adolescent sheep. Ann Thorac Surg 85(2): 587-592.

10. Essop MR, Wisenbaugh T, Sareli P (1993) Evidence against a myocardial factor as the cause of left ventricular dilation in active rheumatic carditis. J Am Coll Cardiol 22(3): 826-829.

11. Figueroa FE, Fernández MS, Valdés P, Wilson C, Lanas F, et al. (2001) Prospective comparison of clinical and echocardiographic diagnosis of rheumatic carditis: Long term follows up of patients with subclinical disease. Heart 85(4): 407-410.

12. Davies C, Sahn D (2001) Detection and significance of subclinical mitral regurgitation by color Doppler techniques. Heart 85(4): 369-370.

13. Wilson NJ, Neutze JM (1995) Echocardiographic diagnosis of subclinical carditis in acute rheumatic fever. Int J Cardiol 50(1): 1-6.

14. David TE (1994) Papillary muscle-annular continuity: Is it important? J Card Surg 9(2 Suppl): 252-254.

15. Burr LH, Krayenbühl C, Sutton MS (1977) The mitral plication suture: A new technique of mitral valve repair. J Thorac Cardiovasc Surg 73(4): 589-595.

For possible submissions Click below: 